\title{
Environmental Risk Factors for Stomach Cancer in an African Setting about 193 Cases at the CHU Point G in Bamako/Mali
}

\author{
Souleymane Sanogo ${ }^{1 *}$, Drissa Traoré1,2, Mamadou Coulibaly ${ }^{3}$, Birama Togola ${ }^{1,2}$, \\ Bréhima Bengaly ${ }^{1,2}$, Ousmane Ibréhima Touré1, Drissa Ouattara1, Bréhima Coulibaly ${ }^{1,2}$, \\ Babou Ba ${ }^{1,2}$, Siaka Diallo', Nouhoum Ongoiba ${ }^{1,2}$
}

${ }^{1}$ Surgery B, CHU Point G, Bamako, Mali

${ }^{2}$ USTTB Faculty of Medicine, Bamako, Mali

${ }^{3}$ Koutiala Regional Hospital, Koutiala, Mali

Email: *sanogosouleymane23@yahoo.fr, *ssanogo93@gmail.com

How to cite this paper: Sanogo, S., Traoré, D., Coulibaly, M., Togola, B., Bengaly, B., Touré, O.I., Ouattara, D., Coulibaly, B., Ba, B., Diallo, S. and Ongoiba, N. (2021) Environmental Risk Factors for Stomach Cancer in an African Setting about 193 Cases at the CHU Point G in Bamako/Mali. Surgical Science, 12, 23-30.

https://doi.org/10.4236/ss.2021.122004

Received: September 24, 2020

Accepted: February 23, 2021

Published: February 26, 2021

Copyright $\odot 2021$ by author(s) and Scientific Research Publishing Inc. This work is licensed under the Creative Commons Attribution International License (CC BY 4.0).

http://creativecommons.org/licenses/by/4.0/ (c) (i) Open Access

\begin{abstract}
CHU (University Hospital Center) Point G: The department of surgery B is a surgical department of CHU Point G. The department is par excellence a reference department for cases of visceral surgery, cancer surgery, cardiovascular surgery, plastic and endocrinology surgery. As a reminder, the CHU Point $\mathrm{G}$ is the largest 3rd level referral hospital in Mali. Aim: To study the environmental risk factors of stomach cancer in the B surgery department of the Point G University Hospital in Bamako. Patients and Methods: We performed a cross-sectional study with retrospective collection from January 2008 to June 2018 (126 months). Results: We have identified 380 cases of digestive cancer, including 193 cases of stomach cancer or $50.79 \%$ of digestive cancers. The mean age of the patients was $57.21 \pm 13$ years. Male sex represented $55 \%(n=106)$. Eating habits were dominated by the consumption of tô with potash (cereal paste) with $64.76 \%(\mathrm{n}=185)$. The main methods of preserving meat and fish were curing and smoking with $57.51 \%(\mathrm{n}=$ 111). Chronic smoking was found in $24.35 \%(\mathrm{n}=47)$, alcohol + tobacco consumption in $2.59 \%(\mathrm{n}=5)$. The low socio-economic class represented 126 cases or $65.38 \%$. Housewives and cultivators were respectively $37.82 \%(\mathrm{n}=$ 73) and $227.97 \%(n=54) .20 .20 \%(n=39)$ had a history of epigastric pain. Epigastralgia was the most common functional sign with $84.5 \%$ of cases $(\mathrm{n}=$ 169). An epigastric mass was found in 72 patients or $37.3 \%$. Adenocarcinoma represented $97.4 \%(n=188)$. Palliative surgery concerned the majority of our patients with $64.8 \%$ of patients $(n=79)$. The postoperative consequences were simple in $28.57 \%$ of cases $(n=28)$, the postoperative morbidity and mortality were respectively $33.61 \%(n=41)$, and $23.77 \%(n=29)$. The overall
\end{abstract}


survival rate after surgery was $10.81 \%$ at 2 years and $2.94 \%$ at 5 years. This rate was $58.83 \%$ at 2 years and $28.50 \%$ at 5 years after curative surgery. Conclusion: The risk factors for stomach cancer are many and varied. Some are particularly present in Africa. Delay in diagnosis due to a belief in traditional healers is common in our community.

\section{Keywords}

Stomach Cancer, Environmental Risk Factors, African Setting, CHU Point G

\section{Introduction}

Stomach cancer is the number one digestive cancer in surgical settings in sub-Saharan Africa [1] [2] [3].

The risk factors are many and varied. Some are particularly present in West Africa. These are poverty, the excessive consumption of tô with potash (cereal paste), the preservation of food by salting and smoking, the low consumption of fruits and vegetables [4]. Delay in diagnosis due to a belief in traditional healers is common and clinical presentations often include signs of obstruction, epigastric mass, Troisier's ganglion. Support poses many problems in front of these locally advanced forms. Between palliative care and curative resection procedures, several questions arise in an environment where chemotherapy remains inaccessible with response rates still uncertain. Our study aimed to assess environmental risk factors for stomach cancer in Africa.

\section{Patients and Methods}

We performed a cross-sectional study with retrospective collection from January 2008 to June 2018 (126 months). To identify our patients, we used the consultation, hospitalization and operative report registers.

Patients were divided into 3 categories of hospitalization according to their financial income. The 1st was that whose patients had good financial income, the 2 nd category being that of those who had average financial income, and the 3 rd that of low financial income. Included in this study were all patients admitted for stomach cancer to our department who were diagnosed on the basis of histology. Patients whose records were unusable were excluded.

The processing of the final report was carried out on Microsoft Exel 2016. The Minitab 18 software was used for the various statistical tests, namely: The Chi2, Yates and Fisher test exact for the comparison of the qualitative variables (according to their conditions application). Student's t test for continuous variables, the sample size being greater than 30 .

The significance level was $5 \%$ for all statistical tests $(\mathrm{p}<0.05)$.

The factors studied were: age, sex, socio-economic factors (categories of hospitalization, profession), socio-food habits (consumption of tô with potash, meat 
and fish preserved by salting and smoking, tobacco, alcohol, fruits and vegetables).

We have not performed a search for Helicobacter pylori. We wanted to study only environmental factors. We considered Helicobacter pylori to be an infectious factor.

The aim was to assess the environmental risk factors for stomach cancer in the B surgery department of the CHU Point G in Bamako/Mali.

\section{Results}

We have identified 380 cases of digestive cancer, including 193 cases of stomach cancer. Or $50.78 \%$ of digestive cancers. The mean age of the patients was $57.21 \pm$ 13 years, Figure 1. The male sex represented 55\% $(n=106)$, the women $45 \%(n$ = 87) with sex ratio M/F of 1.2. The 3rd category of hospitalization (that of patients with low financial income) was the most represented with 126 cases, or $65.28 \%$. Housewives and farmers were the most represented with $37.82 \%(\mathrm{n}=$ $73)$ and $27.97 \%(\mathrm{n}=54)$ respectively. Traders represented $7.77 \%(\mathrm{n}=15)$, manual workers $6.73 \%(\mathrm{n}=13)$, retirees $6.21 \%(\mathrm{n}=12)$, civil servants $5.69 \%(\mathrm{n}=$ $11)$, drivers $2.59 \%(\mathrm{n}=5)$, shepherds and tailors $1.03 \%$ each $(\mathrm{n}=2)$, in $2.07 \%$ the profession was not determined $(n=4)$, Table 1 . Eating habits were dominated by the consumption of tô with potash (cereal paste) with $64.76 \%(\mathrm{n}=125)$, Table 2. The main modes of preserving meat and fish were salting and smoking with $57.51 \%(\mathrm{n}=111)$. Chronic smoking was found in $24.35 \%(\mathrm{n}=47)$, alcohol consumption in $3.10 \%(\mathrm{n}=6)$, The combination of tô with potash and alcohol was consumed in $46.11 \%(\mathrm{n}=89)$, tô + tobacco in $18.13 \%(\mathrm{n}=35)$, smoked fish + tobacco in $17.09 \%(\mathrm{n}=33)$, alcohol + tobacco in $2.59 \%(\mathrm{n}=5)$, fruits and vegetables in $3.10 \%(n=6)$.

History of epigastralgia was found in $20.20 \%(\mathrm{n}=39)$, hypertension $9.32 \%(\mathrm{n}$ $=18)$. We noted 6 cases of diabetes or 3.31\%, 4 cases of HIV (2.07\%), 3 cases of tuberculosis or $1.55 \%, 2$ cases of sickle cell disease or $1.03 \%$ and $1 \%$ of a history of familial cancer is $0.51 \%$.

Epigastralgia represented $87.56 \%$ of cases $(n=169)$. An epigastric mass was found in 72 patients or $37.30 \%$. Adenocarcinoma represented $97.40 \%(\mathrm{n}=188)$. The treatment was essentially surgical with 122 operated, ie $63.21 \%$, Table 3. Some patients (71) (36.78\%) were inoperable due to very advanced tumors. $\mathrm{n}$ only one patient benefited from neoadjuvant chemotherapy, 7 patients from adjuvant chemotherapy (3.62\%), 10 patients from palliative chemotherapy, i.e. $5.18 \%$.

Palliative surgery concerned $64.75 \%$ of operated patients $(n=79 / 122)$ and curative surgery $20.49 \%(\mathrm{n}=25 / 122)$, surgical abstention during surgery in 18 cases, i.e. $14.75 \%$, Table 3 . The postoperative consequences were simple in $28.57 \%$ of cases $(\mathrm{n}=28)$, the postoperative morbidity and mortality were respectively $33.61 \%(n=41)$, and $23.77 \%(n=29)$, Table 4 . The overall survival rate after surgery was $10.81 \%$ at 2 years and $2.94 \%$ at 5 years. This rate was $58.83 \%$ at 2 years and $28.50 \%$ at 5 years after curative surgery. 


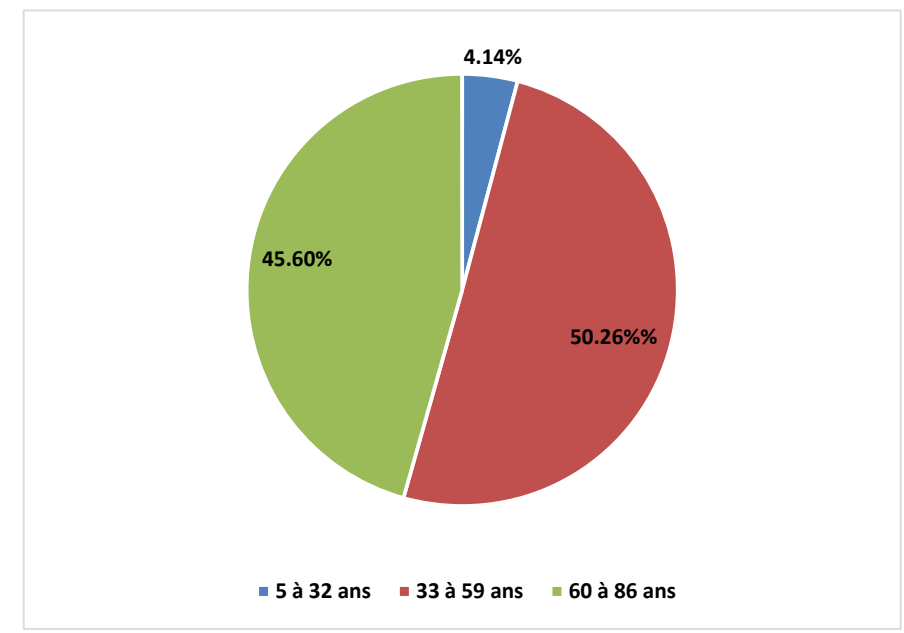

Figure 1. Breakdown by age group.

Table 1. Breakdown by socio-professional activity.

\begin{tabular}{ccc}
\hline Activity & Numbers & Percentage (\%) \\
\hline Housewife & 73 & 37.3 \\
Cultivator & 54 & 28 \\
Worker & 19 & 9.84 \\
Trader & 15 & 7.78 \\
Retired & 12 & 6.22 \\
Diver & 11 & 7.70 \\
Civil servant & 5 & 2.59 \\
Shepherd & 3 & 1.55 \\
Undétermined & 1 & 0.52 \\
Total & 193 & 100 \\
\hline
\end{tabular}

Table 2. Socio-eating habits.

\begin{tabular}{ccc}
\hline Socio-eating habits & Numbers & Percentage (\%) \\
\hline Tô with potash & 125 & 64.76 \\
Smoked fish & 111 & 57.51 \\
Tobacco & 47 & 24.35 \\
Alcohol & 6 & 3.10 \\
Tôo + smoked fish & 89 & 46.11 \\
Tô + Tobacco & 35 & 18.13 \\
Fish + Tàbacco & 33 & 17.09 \\
Alcohol + Tobacco & 5 & 2.59 \\
Fruits and vegetables & 6 & 3.10
\end{tabular}


Table 3. Surgical technique.

\begin{tabular}{|c|c|c|c|}
\hline Surgical Technique & & Numbers & Percentage (\%) \\
\hline \multicolumn{4}{|l|}{ Curative } \\
\hline - Upper polar gastrectomy & $(2 / 3)$ & 1 & 0.82 \\
\hline - Lower polar gastrectomy & $(4 / 5)$ & 24 & 19.67 \\
\hline \multicolumn{4}{|l|}{ Palliative } \\
\hline •Castro-entéro-anastomosis & & 55 & 45.08 \\
\hline -Clean Gastrectomyé & & 19 & 15.57 \\
\hline -Gastrotomy & & 5 & 4.10 \\
\hline Pre-operative abstention & & 18 & 14.75 \\
\hline Total & & 122 & 100 \\
\hline
\end{tabular}

Table 4. Breakdown by post-operative treatment at one month (according to Clavien-Dindo).

\begin{tabular}{|c|c|c|c|}
\hline One-month post-operative treatmer & & Numbers & Percentage (\%) \\
\hline Single suites & & 23 & 28.57 \\
\hline \multicolumn{4}{|l|}{ Grade I } \\
\hline Abdominal pain & 23 & \multirow{5}{*}{32} & \multirow{5}{*}{32.65} \\
\hline Fever & 2 & & \\
\hline Vomiting & 4 & & \\
\hline Wall abscess & 1 & & \\
\hline Dumping Syndrome & 2 & & \\
\hline \multicolumn{4}{|l|}{ Grade II } \\
\hline Severe decompensated anemia & 1 & \multirow{3}{*}{4} & \multirow{3}{*}{4.08} \\
\hline Thrombophlebitis & 2 & & \\
\hline Ascites & 1 & & \\
\hline \multicolumn{4}{|l|}{ Grade IIIB } \\
\hline Dysphagia & 2 & 5 & 5.10 \\
\hline Digestive fistula & 3 & & \\
\hline Grade V (Death) & & 29 & 29.59 \\
\hline Total & & 98 & 100 \\
\hline
\end{tabular}

\section{Discussion}

In our series, stomach cancer accounts for $50.79 \%$ of digestive cancers. There is no significant difference between our rate and that mentioned by DIARRA at the CHU Gabriel Touré in Bamako $\mathrm{p}=0.136$ [4]. This high frequency of stomach cancer in our environment could be explained by a low socio-economic level, a high consumption of salt (preservation of food by curing), a low consumption of fruits and vegetables. On the other hand, these rates are significantly higher than those mentioned by GBESSI in Benin [5] and OUGLOUGA in Togo [6] $\mathrm{p}<$ 0.001 .

This difference could be explained on the one hand by the greater use of cold for the preservation of food and on the other hand to a higher consumption of vegetables and fruits in these different countries.

Our patients were relatively young with a mean age of $57.21 \pm 13$ years. If the average age remains high in developed countries, the relatively young age ob- 
served in our study is superimposed on the results obtained in other developing countries [4] [5] [7] $\mathrm{p} \geq 0.05$. This could be explained by the youth of the African populations.

In our series, stomach cancer predominates in males with an $\mathrm{M} / \mathrm{F}$ sex ratio of 1.2. This predominance is confirmed by ISHANE et al., $2014 \mathrm{p}=0.57$ [7], DIARRA et al., $\mathrm{P}=0.327$ [4]. This male predominance could probably be linked to more frequent alcohol-smoking in males.

Housewives and farmers are the most affected in our series. It must be said that they belong to the underprivileged strata whose vulnerability to cancer is known. Studies have indeed shown that the risk of stomach cancer is 2.5 times greater in the underprivileged [4] [8].

In our series, $64.77 \%$ of patients consumed tô with potash daily. This rate is significantly lower than that reported by another Malian author, $\mathrm{p}<0.05$ [4].

Tô, a cereal paste to which we add potash for longer storage. This food is regularly consumed in West Africa. Its impact on the development of gastric cancer is still very little studied and therefore little known. In-depth epidemiological studies would provide a clear idea of its role in the genesis of gastric cancer.

Regular consumption of fish preserved by salting and smoking was observed in $57.51 \%$ of our patients. This frequent consumption of smoked and salted foods has been reported by some authors from the sub-region [2] [4] [8]. The artisanal activities of smoking and curing fish are widely established in West Africa [2].

We recorded $24.35 \%$ of smoking patients. This rate agrees with that found by OUGLOUGA in Togo [6] $\mathrm{p}=0.367$. On the other hand, it is significantly different from that of DIARRA at the CHU Gabriel Touré in Bamako, $\mathrm{p}<0.05$ [4].

Smoking is a risk factor for stomach cancer with a dose-effect relationship between number of cigarettes per day or length of smoking. Some Japanese and Malaysian studies show that smoking increases stomach cancer by about a factor of 2 [9] [10].

We also recorded $3.11 \%$ of chronic ethyl patients. This rate is lower than those obtained by some African authors $\mathrm{p}<0.05$ [4] [6]. This difference could be linked to the fact that Mali is a predominantly Muslim country, patients rarely admit to alcohol consumption.

The consumption of protective foods, which are fruits and vegetables, was low in our case with $3.1 \%(n=6)$. The same observation was made by Diarra [4] who found $17.7 \%$ of regular consumption of fruit and vegetable. This low consumption of protective food is believed to be due to the lack of financial means.

The ulcerative-bud appearance predominated in our series with $46.92 \%$ of cases. This rate is not significantly different from those reported by GBESSI in Benin GBESSI et al., 2013 [5] $\mathrm{p}=0.011$ and DIARRA et al., $\mathrm{P}=0.051$ [4].

In our study, adenocarcinoma represented $97.40 \%(n=188)$. This histological type constitutes the majority of malignant tumors of the stomach. This rate agrees with those of DIOP in Senegal $\mathrm{p}=0.036$ [2] and GBESSI in Benin $\mathrm{p}=$ $0.020[5]$. 
The resectability rate in our case was $36.07 \%$. This rate agrees with those of DIENG $\mathrm{p}=1$ and ISHANE (ISHANE $\mathrm{p}=0.248$ [7] [11]. On the other hand, this rate differs significantly from those of OKURUMA in Japan and KAYE in the USA $p<0.001$ [12] [13]. This difference could be explained by the fact that tumors are detected very early in developed countries.

The curative procedure consisted of lower polar gastrectomy (4/5) for most cases $(19.67 \%)$ against $64.75 \%$ of gastrointestinal bypass for palliative surgery. This result does not differ from those of SACKO in Mali $p=0.007$ [14]. This technique (lower polar gastrectomy) is the reference procedure in non-ilitis antral tumors.

The bypass-type palliative surgical procedures also predominated in the DIOP series $p=0.851$ [2]. They were aimed at alleviating complete gastric stenosis and its consequences. Immediate results were appreciable with cessation of vomiting and a resumption of normal feeding. They are justified in our context where alternatives are almost non-existent.

We recorded a morbidity of $33.61 \%$. This rate differs significantly from those of DIENG in Senegal $p<0.001$ [11]. This difference could be explained by the lack of resuscitation means in our structure.

We recorded a death rate of 23.77 . With as an endpoint, any mortality occurring within one month of surgery.

Our rate agrees with those of DEMBELE and DIENG $p>0.005$ [11] [15]. On the other hand, our rate differs significantly from that reported by OKUMURA in Japan $\mathrm{p}<0.001$ [12]. This difference could be explained by earlier treatment of patients in developed countries.

The overall survival rate after surgery was $10.81 \%$ at 2 years and $2.94 \%$ at 5 years. This rate was $58.83 \%$ at 2 years and $28.50 \%$ at 5 years after curative surgery. Our survival rate does not differ significantly from that of DIOP and DIENG $\mathrm{p}=1$ [2] [11]. According to some authors, even palliative gastric resection seems to improve the survival rate compared to palliative surgery without resection [14] [15] [16].

\section{Conclusion}

The risk factors for stomach cancer are many and varied. Some are particularly present in Africa. Delay in diagnosis due to a belief in traditional healers is common in our community.

\section{Conflicts of Interest}

The authors declare no conflicts of interest regarding the publication of this paper.

\section{References}

[1] Asombang, A.W. and Kelly, P. (2012) Gastric Cancer in Africa: What Do We Know about Incidence and Risk Factors. Transactions of the Royal Society of Tropical 
Medicine and Hygiene, 106, 69-74. https://doi.org/10.1016/j.trstmh.2011.11.002

[2] Diop, B., Dia, A.A., Ba, P.A., et al. (2017) Surgical Management of Gastric Tumors in Dakar: About 36 Observations. Health Sciences and Diseases, 18, 4.

[3] Zare, C., Some, O.R., Ouangre, E., Zida, M., et al. (2017) Digestive Cancers in the General and Digestive Surgery Department of the CHU Sanou Sourô in Bobo-Dioulasso: State of Play. Burkina Medical, 21, 1.

[4] Diarra, M.T., Konate, A., Diarra, A.N., et al. (2014) Epidemiological and Prognostic Characteristics of Stomach Cancer in Rural Areas in Mali. Mali Medical, 29, 45-48.

[5] Gbessi, D.G., Dossou, F.M., Soton, R.R., Seto, D.M., et al. (2013) Anatomo-Clinical Aspects of Stomach Cancer in Benin. Le Bénin Médical, 53, 33-37.

[6] Ouglouga, O., Lawson-Ananissoh, L.M., Bagny, A., et al. (2015) Stomach Cancer: Epidemiological, Clinical and Histological Aspects at the CHU Campus de Lome (Togo). Médecine et Santé Tropicales, 25, 65-68. https://doi.org/10.1684/mst.2014.0415

[7] Ihsane, M., Nawal, L., Bahija, B., et al. (2014) Epidemiology of Gastric Cancer: Experience from a Moroccan Hospital. Pan African Medical Journal, 17, 42.

[8] Diallo, A.D., Diallo, A.T., Camara, A.K., et al. (2016) Stomach Cancer: Epidemiology, Management and Prognosis in the Visceral Surgery Department of the Donka National Hospital, CHU of Conakty-Guinea. Journal of Surgery of Central Africa (RECAC), 2, 9.

[9] Kuo, H.H., Wu, C., et al. (2010) Palliative Resection in Patients with Uncurable Gastric Cancer. World Journal of Surgery, 34, 1015-1021.

https://doi.org/10.1007/s00268-010-0467-7

[10] Fock, K.M., Chiba, T., Uemura, N., et al. (2008) Asia-Pacific Consensus Guidelines on Gastric Cancer Prevention. Journal of Gastroenterology and Hepatology, 23, 351-365. https://doi.org/10.1111/j.1440-1746.2008.05314.x

[11] Dieng, M., Sawadogo, T.J., Ka, O., et al. (2005) Surgical Treatment at the Aristide le Dantec CHU in Dakar from 1995 to 2005. Journal Africain de Chirurgie Digestive, 10, 1059-1062.

[12] Okuma, P.Y., Hiroharu, Y., Susumu, A., et al. (2014) Palliative Distal Gastrectomy Offers No Survival Benefit over Gastrojejunostomy for Gastric Cancer with Outlet Obstruction: Retrospective Analysis of an 11-Year Experience. World Journal of Surgical Oncology, 12, 364. https://doi.org/10.1186/1477-7819-12-364

[13] Kaye, M., Rreid, L., Greer, G., et al. (2014) Treatment of Gastric Adenocarcinoma May Differ among Hospital Types in the United States, a Report from the National Cancer Data Base. Journal of Gastrointestinal Surgery, 11, 410-420. https://doi.org/10.1007/s11605-006-0040-8

[14] Sacko, O., Soumare, L., Camara, A., et al. (2014) Management of Gastric Malignancies in Surgery Department A of CHU Point G in 84 Cases. Mali Medical, 29, 4.

[15] Dembele, B.T., Togo, A., Kante, L., et al. (2012) Unresectable Gastric Cancers in the General Surgery Department CHU Gabriel Touré Bamako. Mali Medical, 27, 14-18.

[16] Some, O.R., et al. (2018) Place of Gastrectomy in the Management of Stomach Cancer: About 68 Cases in Bobo-Dioulasso. African Journal of Surgery, 5, 67-74. 